\title{
Cushing's Syndrome Due to Huge Nodular Adrenocortical Hyperplasia with Fluctuation of Urinary 17-OHCS Excretion
}

\author{
SHINYA MAKINO, Kozo HASHIMOTO, MARIKo SUGIYAMA \\ Ryuto HIRASAWA, Toshihiro TAKAO, Zensuke 'OTA, \\ Michinao SAEGUSA*, Teruhisa OHASHI* and Hiroyuki OMORI*
}

Third Department of Internal Medicine and Department of Urology*, Okayama University Medical School, Okayama 700, Japan

\begin{abstract}
A 51-yr-old male patient with Cushing's syndrome due to huge nodular adrenocortical hyperplasia is described. Urinary 17-OHCS was not suppressed by a high dose of $(8 \mathrm{mg})$ dexamethasone and showed rather a tendency to paradoxical response. There was no response to metyrapone. Plasma cortisol showed a hyperresponse to insulin-induced hypoglycemia and a rapid response to corticotropin releasing hormone-lysine vasopressin (CRH-LVP) administration without an obvious ACTH response. Plasma cortisol responded to synthetic ACTH. Urinary 17-OHCS did not show parallel changes with plasma cortisol. These results and computerized tomography data suggested huge multiple nodular adrenocortical hyperplasia, which was confirmed later by surgery. The left and right adrenal glands weighed 105 and $45 \mathrm{~g}$, respectively. Hyperreaction of the adrenal gland to a small change in plasma ACTH or "unknown factors" may cause not only the discrepancy between cortisol and ACTH response but also the development of autonomous nodules in the adrenal gland.
\end{abstract}

We previously reported a case of Cushing's syndrome due to huge nodular adrenocortical hyperplasia (Hashimoto et al., 1986). In that case, plasma cortisol responded to insulin-induced hypoglycemia without an obvious ACTH response. In view of the in vitro experiment results, we suggested that plasma cortisol responded

\section{Received March 8, 1989}

The address: SHINYA MAKINO, M. D.

Third Department of Internal Medicine, Okayama University Medical Schoo1, 2-5-1 Shikata-cho, Okayama, 700, Japan to a slight change in plasma ACTH which was not detected by ACTH radioimmunoassay, or to unknown factors other than ACTH which might be increased in plasma by hypoglycemia. In this paper, we report another case of huge nodular adrenocortical hyperplasia with a similar discrepancy between cortisol and ACTH response to insulin-induced hypoglycemia. A fluctuation in urinary 17-OHCS was observed in this patient, and we also found a tendency to paradoxical response of urinary 17-OHCS to dexamethasone. 


\section{Case Reports}

A 51-yr-old male was admitted to our hospital with hypertension and edema in September, 1987. Hypertension was pointed out at 48 yrs of age. Edema in lower extremities appeared at 49 yrs of age and increased three months before admission. His medical history revealed lung tuberculosis at $15 \mathrm{yrs}$ of age. The patient's father had hypertension and his mother died of gastric cancer.

Physical examination revealed that the patient had a moon face, buffalo hump, hirsutism, gynecomastia, telangiectasia in the face, purpura in the truncus and extremities, and pretibial edema. There was no striae cutis distensae. His body height was $168 \mathrm{~cm}$ and body weight $56 \mathrm{~kg}$. Blood pressure was $180 / 114 \mathrm{mmHg}$.
Laboratory findings revealed a red blood cell count of $422 \times 10^{4} / \mathrm{mm}^{3}$; hemoglobin, $13.4 \mathrm{~g} / \mathrm{d} 1$; and hematocrit, $40.6 \%$. The white blood cell count was $12300 / \mathrm{mm}^{3}$ with $95 \%$ neutrophils and platelet count $22.3 \times 10^{4} / \mathrm{mm}^{3}$. Serum electrolytes were: $\mathrm{Na} 143 \mathrm{mEq} / 1$; K $3.1 \mathrm{mEq} / 1 ; \mathrm{C} 1104 \mathrm{mEq} / 1$, and $\mathrm{Ca} 8.3 \mathrm{mg} / \mathrm{d} 1$. Serum BUN was 21.9 $\mathrm{mg} / \mathrm{dl}$; creatinine, $1.01 \mathrm{mg} / \mathrm{dl}$; and uric acid, $5.6 \mathrm{mg} / \mathrm{dl}$. Total serum protein was $6.16 \mathrm{~g} / \mathrm{dl}$ with $58.6 \%$ albumin; GOT, $30 \mathrm{IU} / 1$; GPT, $33 \mathrm{IU} / 1$; LDH, $808 \mathrm{IU} / 1$; $\gamma$-GTP, $80 \mathrm{IU} / 1$; and total cholesterol, $246 \mathrm{mg} / \mathrm{d} 1.75 \mathrm{~g}$ GTT : blood glucose concentrations were 135,212 , 256,258 and $280 \mathrm{mg} / \mathrm{dl}$ at $0,30,60,90$ and $120 \mathrm{~min}$, respectively. Urinalysis showed proteinuria $(+)$.

\section{Endocrinological examinations}

The baseline hormone levels are shown in Table 1. Plasma ACTH was always at

Table 1. Baseline endocrine data and provocative tests of pituitary hormones

\begin{tabular}{|c|c|c|c|c|c|}
\hline \multicolumn{3}{|c|}{ Examination } & Patients' value & & Normal value \\
\hline \multicolumn{3}{|c|}{ Urinary 17-OHCS (mg/day) } & $3.01-28.86$ & & $3-9$ \\
\hline \multirow{2}{*}{\multicolumn{3}{|c|}{$\begin{array}{l}\text { Urinary } 17-\mathrm{KS} \text { (mg/day) } \\
\text { Plasma cortisol diurnal rhythm }(\mu \mathrm{g} / \mathrm{dl})\end{array}$}} & $5.14-9.53$ & & $3-9$ \\
\hline & & & & & \\
\hline & \multicolumn{2}{|c|}{$9: 00$} & 22.4 & & $5.4-22.6$ \\
\hline & \multicolumn{2}{|c|}{$16: 00$} & 25.6 & & \\
\hline & \multicolumn{2}{|c|}{$23: 00$} & 20.0 & & \\
\hline \multirow{2}{*}{\multicolumn{3}{|c|}{$\begin{array}{l}\text { Plasma } \text { ACTH (pg/ml) } \\
\text { Plasma renin activity (ng/m1/hr) }\end{array}$}} & n.d. & & $10-75$ \\
\hline & & & 2.33 & & $0.4-2.4$ \\
\hline \multicolumn{3}{|c|}{ Plasma aldosterone $(\mathrm{pg} / \mathrm{ml})$} & 79.0 & & $15-125$ \\
\hline \multicolumn{3}{|c|}{ Plasma DOC $(\mathrm{ng} / \mathrm{ml})$} & 0.657 & & $0.08-0.278$ \\
\hline \multicolumn{3}{|c|}{ Plasma DHEA (ng/ml) } & 0.253 & & $1.2-7.5$ \\
\hline \multicolumn{3}{|c|}{ Plasma DHEA-sulfate $(\mathrm{ng} / \mathrm{ml})$} & 87.3 & & $400-1500$ \\
\hline \multicolumn{3}{|c|}{ Plasma norepinephrine $(\mathrm{ng} / \mathrm{ml})$} & 0.11 & & $0.05-0.40$ \\
\hline \multicolumn{3}{|c|}{ Plasma epinephrine (ng/m1) } & 0.14 & & $<0.10$ \\
\hline \multicolumn{3}{|c|}{ Serum T3 (ng/d1) } & 108.1 & & $80-200$ \\
\hline \multicolumn{3}{|c|}{ Serum T4 $(\mu \mathrm{g} / \mathrm{d} 1)$} & 7.5 & & $4.5-11.5$ \\
\hline \multicolumn{6}{|c|}{ TRH + LHRH test } \\
\hline & 0 & 15 & 30 & 60 & $90(\min )$ \\
\hline PRL (ng/ml) & 15.4 & 24.9 & 24.8 & 18.8 & 18.3 \\
\hline $\mathrm{TSH}(\mu \mathrm{U} / \mathrm{ml})$ & 1.35 & 3.70 & 5.13 & 4.91 & 4.40 \\
\hline $\mathrm{LH}(\mathrm{mIU} / \mathrm{ml})$ & 10.1 & 34.8 & 50.4 & 51.8 & 40.9 \\
\hline $\mathrm{FSH}(\mathrm{mIU} / \mathrm{ml})$ & 5.5 & 9.0 & 11.1 & 12.2 & 12.1 \\
\hline \multicolumn{6}{|c|}{ Insulin test } \\
\hline $\mathrm{GH}(\mathrm{ng} / \mathrm{m} \mathrm{l})$ & 0.1 & & 0.2 & 0.2 & 0.2 \\
\hline
\end{tabular}


an undetectable level. Plasma cortisol and urinary 17-OHCS were normal or increased, while urinary 17-KS was within the normal range. Urinary catecholamines, plasma renin activity and the plasma aldosterone concentration were normal. Plasma deoxycorticosterone was increased, while plasma DHEA and DHEA-sulfate were low. Serum $\mathrm{T}_{3}$ and $\mathrm{T}_{4}$ were also within the normal range. Plasma cortisol did not show a diurnal rhythm.

High doses of dexamethasone $(8 \mathrm{mg}$ : $2 \mathrm{mg}$ every $6 \mathrm{hr}$ ) were administered in October 7-8 and November 21-22, when baseline urinary $17-\mathrm{OHCS}$ was normalized spontaneously and then elevated again (Fig. 1). Dexamethasone failed to suppress urinary $17-\mathrm{OHCS}$ and $17-\mathrm{KS}$ and, paradoxically, rather tended to increase urinary 17-OHCS. Metyrapone (500 mg every $4 \mathrm{hr}$

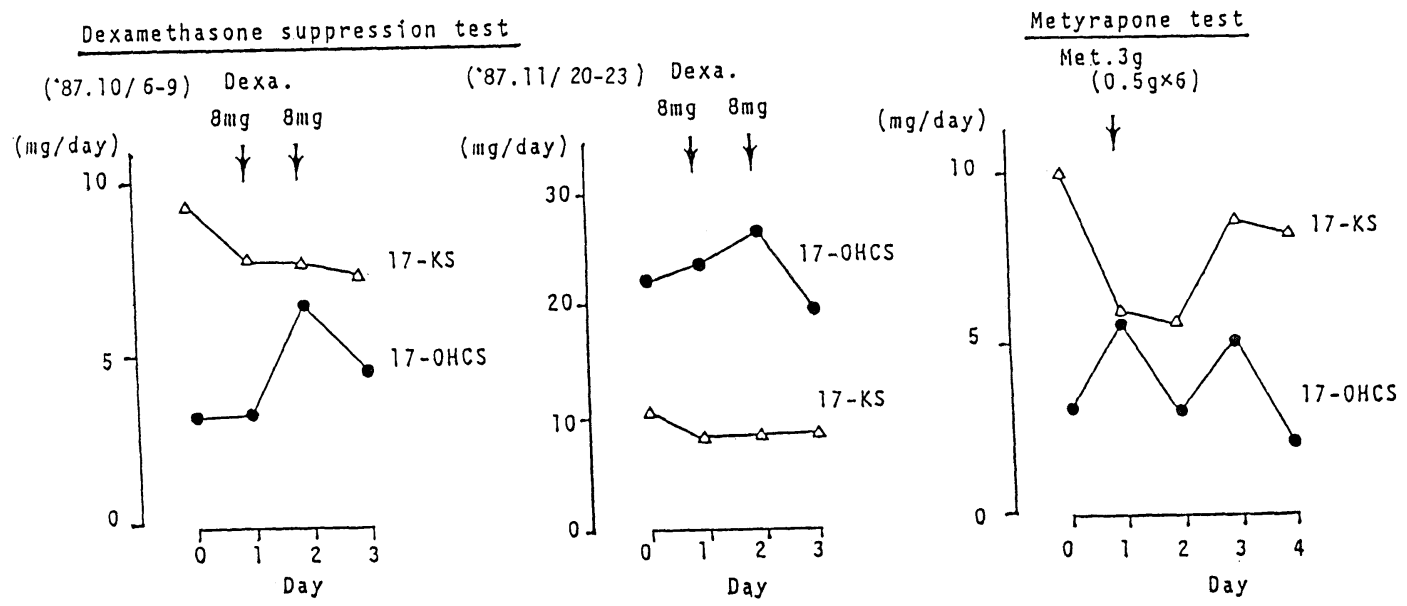

Fig. 1. Urinary 17-OHCS response to high doses $(8 \mathrm{mg})$ of dexamethasone (Dexa, $2 \mathrm{mg}$ given orally every $6 \mathrm{hr}$ for 2 days) and metyrapone (Met, $0.5 \mathrm{~g}$ given orally every $4 \mathrm{hr}$ for 6 times: total $3 \mathrm{~g}$ ).
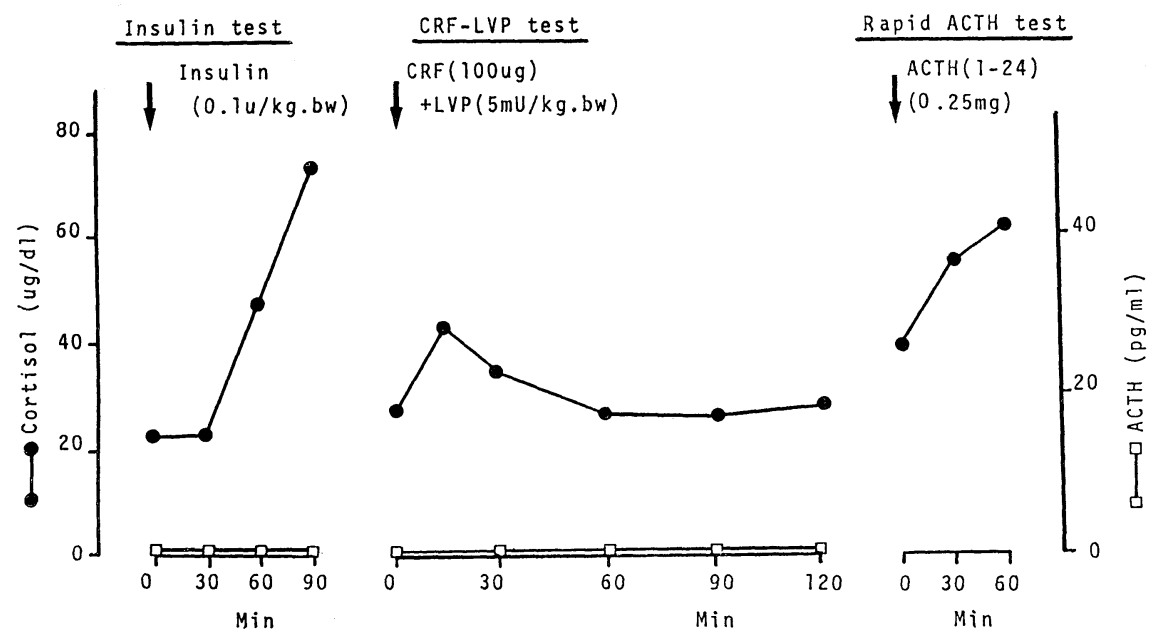

Fig. 2. Provocative tests of pituitary-adrenal function in the patient. Regular insulin $(0.1 \mathrm{U} /$ $\mathrm{kg})$, ovine CRF $(1 \mu \mathrm{g} / \mathrm{kg})+\mathrm{LVP}(5 \mathrm{mU} / \mathrm{kg})$ or $1-24 \mathrm{ACTH}(0.25 \mathrm{mg})$ was given iv. 
for $24 \mathrm{hr}$, total $3 \mathrm{~g}$ ) had no effect on urinary 17-OHCS (Fig. 1). In the insulin tolerance test (regular insulin $0.1 \mathrm{U} / \mathrm{kg}$, iv) the blood glucose concentration decreased from $104 \mathrm{mg} / \mathrm{dl}$ to $42 \mathrm{mg} / \mathrm{dl}$ at $30 \mathrm{~min}$. Plasma ACTH stayed at an undetectable level, while plasma cortisol showed a hyperresponse (Fig. 2). Plasma cortisol showed a rapid response to an iv administration of ovine CRH $(100 \mu \mathrm{g})$ and $\mathrm{LVP}(5 \mathrm{mU} / \mathrm{kg})$, whereas plasma ACTH stayed at an undetectable level. Plasma cortisol responded normally to an iv administration of $0.25 \mathrm{mg}$ 1-24 ACTH (Cortrosyn) (Fig. 2).

The basal concentrations of serum GH, LH, FSH, PRL, TSH were within the normal range (Table 1). Serum GH showed no response to insulin-induced hypoglycemia. In the LH-RH $(0.1 \mathrm{mg}$, iv) and TRH $(0.5 \mathrm{mg}$, iv) test, serum LH and FSH responded normally, whereas PRL and TSH showed low responses. All hormones were measured with commercially available radioimmunoassay kits (ACTH: C.I.S. Gifsur-Yvette, France; cortisol, LH, FSH : Daiichi Radio-

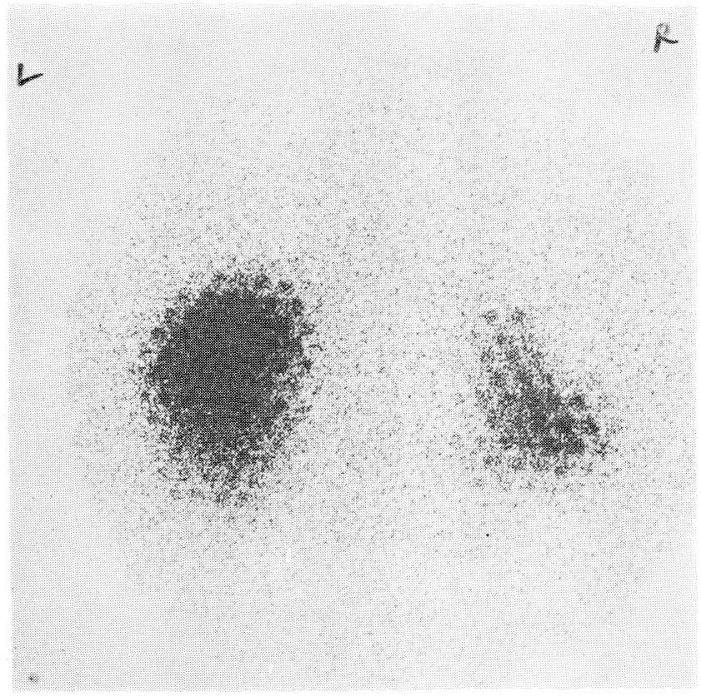

Fig. 3. Adrenocortical scintigram using ${ }^{131} \mathrm{I}-$ adosterol without dexamethasone suppression. isotope Laboratories, Tokyo, Japan; GH, PRL, TSH: Dainabot Co. Tokyo, Japan).

An adrenocortical scintigram with ${ }^{131}$ Iadosterol revealed a large bilateral uptake of the tracer with a higher concentration on the left side (Fig. 3). Computerized tomography showed an enlarged multinodular mass in both adrenal glands (Fig. 4). Skull X-ray and cranial $C T$ revealed no abnormal findings.

\section{Fluctuation of urinary 17-OHCS}

These findings led us to suspect a huge bilateral nodular adrenocortical hyperplasia with hypersecretion of cortisol. Moreover,
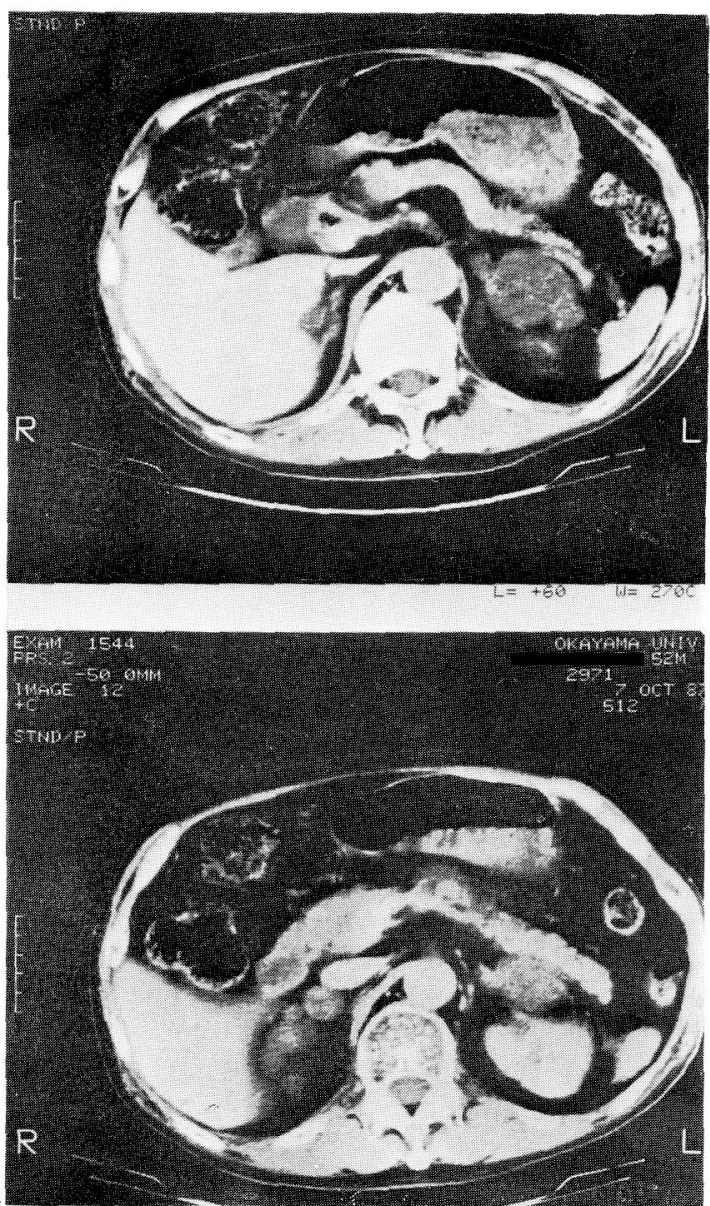

Fig. 4. Computed tomography of adrenal gland. 
in this case, urinary 17-OHCS showed a spontaneous normalization 3 days after admission (Fig. 5), whereas urinary 17-KS

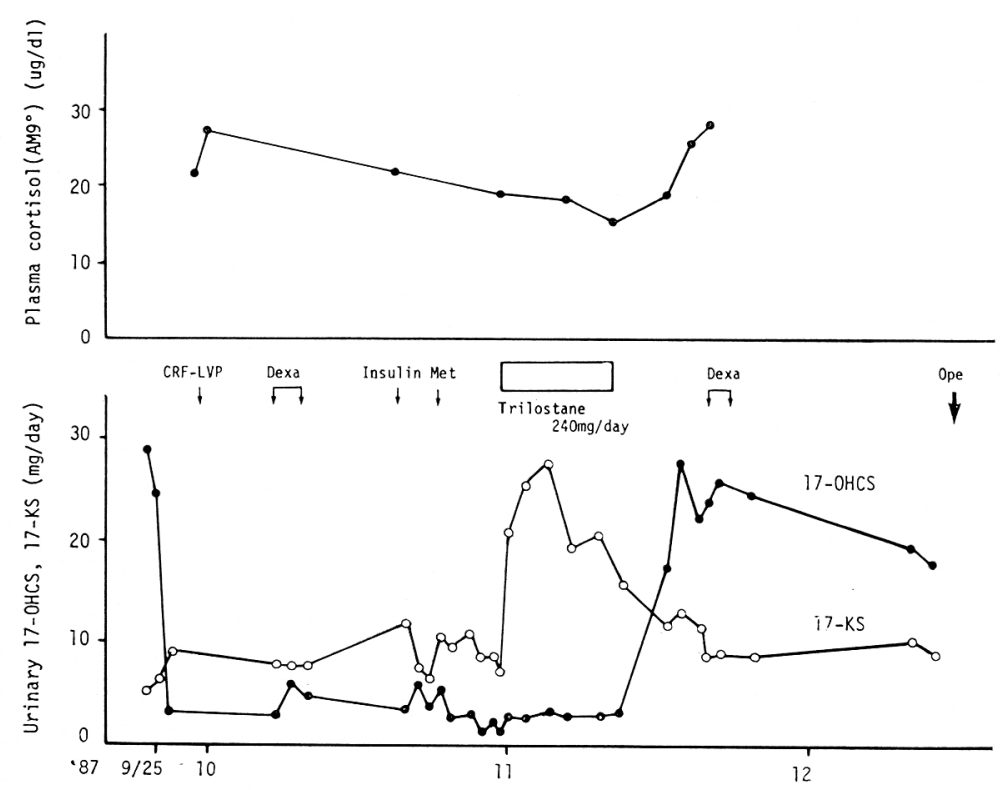

Fig. 5. Urinary 17-OHCS, 17-KS excretions and plasma cortisol levels before surgery. CRF-LVP: CRF-LVP test, Dexa: dexamethasone suppression test, Insulin: insulin test, Met: metyrapone test. stayed at the upper limit of the normal range. When we treated the patient with trilostane $(240 \mathrm{mg} /$ day) for 2 weeks, urinary 17-OHCS stayed near the lower limit of the normal range, whereas urinary $17-\mathrm{KS}$ was increased. Urinary 17 OHCS was increased again after the patient stopped taking trilostane, and the high concentration continued until operation. During the period when urinary 17-OHCS was normalized, no parallel reduction in plasma cortisol was evident. Plasma cortisol in the morning sometimes tended to be reduced to the upper limits of the normal range during trilostane administration.

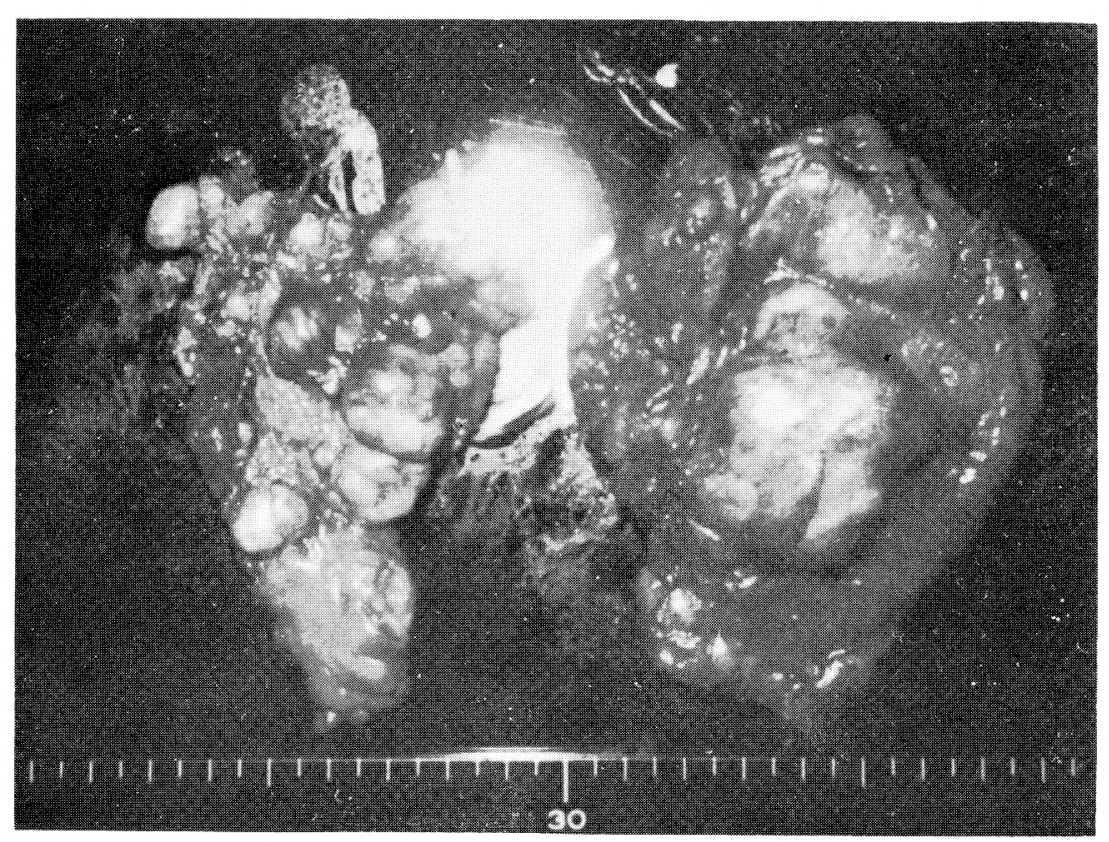

Fig. 6. Macroscpic findings for bilateral adrenal gland. 


\section{Surgical and morphological findings}

Total bilateral adrenalectomy was performed on December 15, 1987. The bilateral adrenal glands were enlarged with huge multiple nodules. The cut surface of the nodules was yellowish in color. The left and right adrenals measured $10.0 \times 8.2 \times 2.0$ $\mathrm{cm}$ and $8.8 \times 6.4 \times 1.6 \mathrm{~cm}$ and weighed 105 and $45 \mathrm{~g}$, respectively (Fig. 6). Microscopic examination showed that the nodules were encapsulated and were composed mainly of clear cells. Brown granules were not abundant. The surrounding areas showed compressed and atrophic cortical cells. There was no evidence of malignancy (Fig. 7).

\section{Clinical course}

Since the operation the patient has been treated with hydrocortisone. Eight months after surgery, the plasma ACTH concentration at $0900 \mathrm{hr}$ was $42.8 \mathrm{pg} / \mathrm{ml}$, and the signs and symptoms of Cushing's syndrome have grandually disappeared.

\section{Discussion}

We present a case of Cushing's syndrome due to huge nodular adrenocortical hyperplasia which was confirmed in surgery. Bilateral adrenocortical hyperplasia is present in approximately $70-80 \%$ of Cushing's syndrome cases. Bilateral nodular hyperplasia accounts for $15-20 \%$ of all cases of adrenocortical hyperplasia (Neville and Symington, 1967). Adrenocortical nodules have been classified into three groups depending on their size and weight, and huge nodules are defined as those $90-100 \mathrm{~g}$ in weight (Hashimoto et al., 1986). Although the pathogenesis of adrenocortical nodular hyperplasia has not been clear, two main hypothesis have been postulated. First, it is pituitary dependent because of the high

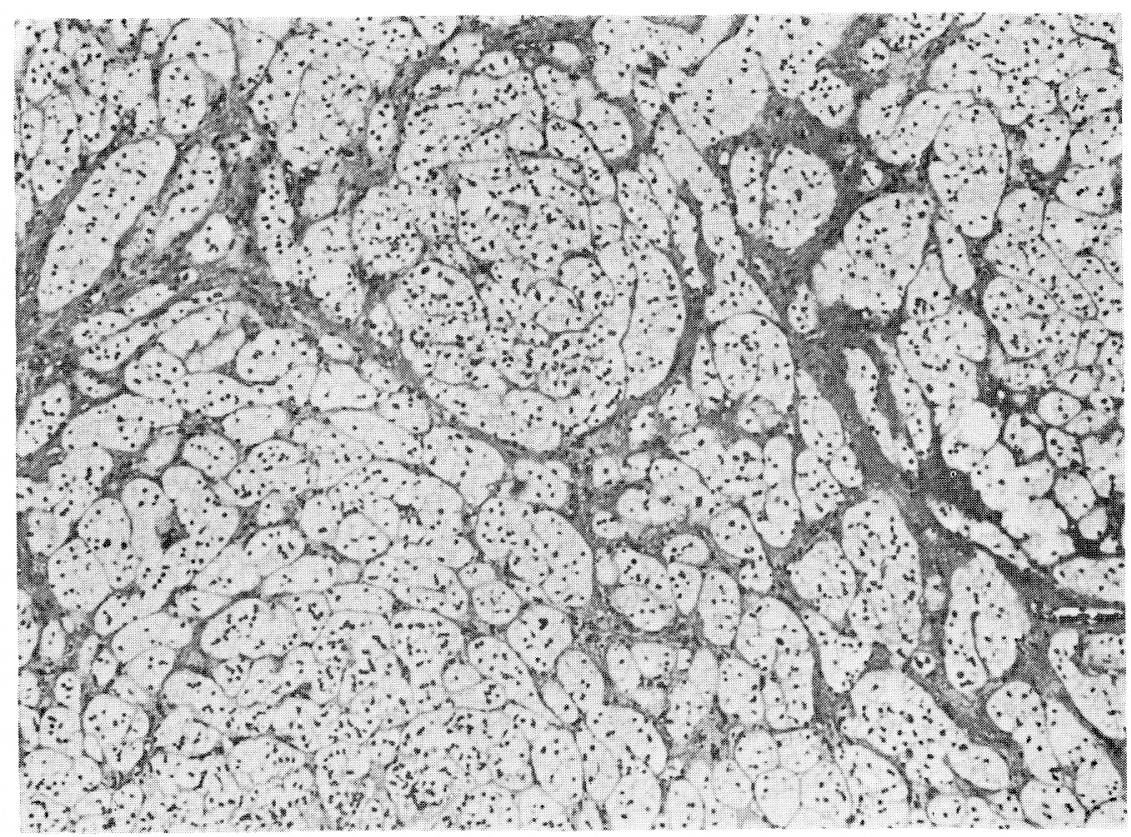

Fig. 7. Histological findings. 
ACTH concentration after adrenalectomy (Choi et al., 1970; Hidai et al., 1975), the coexistence of pituitary adenoma (Aron et al., 1981) or the development of pituitary adenoma after adrenalectomy (Raux et al., 1975), and so on. Second, it is primarily an adrenal disorder because of the lack of response of plasma ACTH to LVP and metyrapone, the paradoxical response of urinary 17-OHCS to dexamethasone, and the atrophic adjacent areas of the adrenal gland, and so on (Meador, 1967; Ruder et al., 1974; Shenoy et al., 1984). Several authors (Levin, 1966; Cohen, 1966; Choi et al., 1970; Ishihara et al., 1977; Smals et al., 1983; Miura et al., 1984) have suggested that initial hypersecretion of ACTH gradually leads to the development of adrenocortical hyperplasia, which finally produces semi-autonomous or autonomous nodules, and then the hypothalamo-pituitary system is suppressed due to a negative feedback mechanism. Therefore, each case shows varying degrees of pituitary dependence and adrenocortical autonomy. The suppression by high dose dexamethasone and the response to metyrapone is usually observed in the early stages but not in later stages of this disorder. In this case, the patient had low plasma ACTH, no suppression of urinary 17-OHCS by $8 \mathrm{mg}$ dexamethasone and no response to metyrapone. Plasma ACTH has been normalized and is not elevated eight months after surgery. Furthermore, the microscopic findings revealed that the surrounding areas were atrophic. These data suggest that this case might have adrenocortical autonomy rather than pituitary dependence, although further follow up will be needed to confirm this.

Spontaneous fluctuation of ACTH and/ or cortisol secretion have been found in Cushing's syndrome due to pituitary adenoma (Brown et al., 1973; Liberman et al., 1976; Sakiyama et al., 1984; Atkinson et al., 1985), ectopic ACTH-producing tumor (Bailey, 1971; Chajek and Romanoff, 1976;
Estopinan et al., 1987) and adrenal adenoma (Green et al., 1975). The cycle periods ranged from 7 to 85 days. Plasma ACTH, cortisol and urinary 17-OHCS generally showed parallel changes. In this case, urinary 17-OHCS showed spontaneous normalization and was then increased again. As we followed this case up only three months before the operation, we may not diagnose this case as 'cyclic' Cushing's syndrome. Longer term follow up might have led us to diagnose cyclic hormonogenesis. However, in this case, urinary 17-OHCS changes did not parallel plasma cortisol changes. This might indicate that a disorder of cortisol metabolism is present in this case. But we could not find any disorder affecting corticosteroid metabolism; for example, hypothyroidism and severe liver damage. We could not find the cause of spontaneous normalization (Shimizu and Tanaka, 1984).

The pardoxical response to dexamethasone has been described in micronodular adrenocortical dysplasia (Ruder et al., 1974), adrenal adenoma or carcinoma (Scott et al., 1962) and, most frequently, pituitary adenoma (Linn et al., 1967 ; French et al., 1969) without cyclic hormonogenesis. French et al. (1969) suggested that this phenomenon might result from upsetting of a negative feedback effect of glucocorticoid or a paradoxical positive feedback stimulation of ACTH. However, Brown et al. (1973) suggested that the paradoxical response to dexamethasone might happen to coincide with the upward slope of the hormonal cycle in cyclic Cushing's syndrome, and that one should carefully examine periodicity if it is observed. In fact, other investigators (Liberman et al., 1976; Estopinan et al., 1987) have also reported that this phenomenon occurred coincidentally with high levels of cortisol secretion in cyclic Cushing's syndrome. On the other hand, in increasingly recognized cases of cyclic Cushing's syndrome, a paradoxical response to dexamethasone has been observed during pe- 
riods with normal cortisol baseline levels (Atkinson et al., 1985) and normal suppression by low dose dexamethasone in a hormonally normalized period (Sakiyama et al., 1984). Thus, the mechanisms of paradoxical response has not been clarified, and it is neceassry to recognize the variation in the dexamethasone suppressibility in cyclic Cushing's syndrome. In this case, urinary $17-\mathrm{OHCS}$ tended to show a paradoxical response to dexamethasone, especially when the basal urinary $17-\mathrm{OHCS}$ concentration was low.

We have already reported a very similar case with huge nodular adrenocortical hyperplasia (Hashimoto et al., 1985). In that case, cortisol also responded to insulininduced hypoglycemia without an obvious plasma ACTH response. The In vitro experiment revealed that the nodular tissue showed a cortisol response to ACTH but not to other substances which might be increased in peripheral blood by insulininduced hypoglycemia. We speculated that cortisol might respond to other doses of such substances, to other different substances or to a slight change in plasma ACTH which was not detected by $\mathrm{ACTH}$ radioimmunoassay. In this case, the patient showed the same discrepancy between cortisol and ACTH response, not only to insulin-induced hypoglycemia but also to intravenous administration of CRH-LVP. In this patient, similar features are felt to be the cause of plasma cortisol response without obvious ACTH response. In this patient, plasma cortisol responded more strongly to insulin-induced hypoglycemia than exogeneous 1-24 ACTH. This suggests that cortisol responded to some "unknown factors" which might be increased in plasma in insulin-induced hypoglycemia. We cannot conclude from the present results what the "unknown factors" are in this case. However, we emphasise again that the discrepancy between ACTH and cortisol response may be one of the char- acteristics in huge nodular adrenocortical hyperplasia. "Unknown factors", which might induce this discrepancy, might also be responsible for the development of adrenal nodules.

\section{References}

Aron, D. C., J. W. Findling, P. A. Fitzgerald, R. M. Brooks, F. E. Fisher, P. H. Forsham and J. B. Tyrrel (1981). Pituitary ACTH dependency of nodular adrenal hyperplasia in Cushing's syndrome. Report of two cases and review of the literature. Am. J. Med. 71, 302-306.

Atkinson, A. B., A. L. Kennedy, D. J. Carson, D. R. Hadden, J. A. Weaven and B. Sheridan (1985). Five cases of cyclic Cushing's syndrome. British Med. J. 291, 1453-1457.

Bailey, R. E. (1971). Periodic hormonogenesisA new phenomenon. Periodicity in function of a hormone-producing tumor in man. $J$. Clin. Endocrinol. Metab. 32, 317-327.

Brown, R. D., G. R. Van Loon, D. N. Orth and G. W. Liddle (1973). Cushing's disease with periodic hormonogenesis : One explanation for paradoxical response to dexamethasone. $J$. Clin. Endocrinol. Metab. 43, 913-918.

Chajek, T. and H. Romanoff (1976). Cushing syndrome with cyclical edema and periodic secretion of corticosteroids. Arch. Intern. Med. 136, 441-443.

Choi, Y., E. E. Werk, Jr. and L. J. Sholiton (1970). Cushing's syndrome with dual pituitary-adrenal control. Arch. Intern. Med. 125, 1045-1049.

Cohen, R. B. (1966). Observation on cortical nodules in human adrenal grands: Their relationship to neoplasia. Cancer 19, 552-556.

Estopinan, V., C. Varela, P. Riobo, J. R. Dominguez and J. Sancho (1987). Ectopic Cushing's syndrome with periodic hormonogenesis - a case suggesting a pathogenetic mechanism. Postgraduate Med. J. 63, 887889.

French, F. S., J. A. Macfie, B. Baggett, T. F. Williams and J. J. Van Wyk (1969). Cushing's syndrome with a paradoxical response to dexamethasone. Am. J. Med. 47, 619-624.

Hashimoto, K., Y. Kawada, K. Murakami, T. Hattori, S. Suemaru, J. Kageyama, Z. Ota, 
S. Hayata, T. Ohashi and H. Omori (1986). Cortisol responsiveness to insulin-induced hypoglycemia in Cushing's syndrome with huge nodular adrenocortical hyperplasia. Endocrinol. Japon. 33, 479-487.

Hidai, H., H. Fujii, K. Otsuka, K. Abe and N. Shimizu (1975). Cushing's syndrome due to huge adrenocortical multinodular hyperplasia. Endocrinol. Japon. 22, 555-560.

Ishihara, T., F. Uchihara, M. Tatsumi, T. Mori, T. Igarashi, H. Takayama and T. Ishikawa (1977). A case with Cushing syndrome due to huge bilateral adrenal nodular hyperplasia. Folia Endocrinol. Jap. 53, 1082-1093. (In Japanese).

Levin, M. E. (1966). The development of bilateral adenomatous adrenal hyperplasia in a case of Cushing's syndrome of eighteen years' duration. Am. J. Med. 40, 318-324.

Liberman, B., B. L. Wajchenberg, M. A. Tambascia and C. H. Mesquita (1976). Periodic remission in Cushing's disease with paradoxical dexamethasone response: An expression of periodic hormonogenesis. J. Clin. Endocrin. Metab. 43, 913-918.

Linn, Jr., J. E., B. Bowdoin, T. A. Former and C. K. Meador (1967). Observation and comments on failure of dexamethasone suppression. New England J. Med. 277, 403-405.

Meador, C. K., B. Bowdoin, W. C. Owen, Jr. and T. A. Farmer, Jr. (1967). Primary adrenocortical nodular dysplasia: A rare cause of Cushing's syndrome. J. Clin. Endocrinol. Metab. 27, 1255-1263.

Miura, M., Y. Matsukado, T. Kodama and R. Hiramatsu (1984). Adrenocortical nodular hyperplasia of the Cushing's disease: Diagnosis and surgical treatment. No shinkei Geka 12, 689-696. (In Japanese).

Neville, A. M. and T. Symington (1967). The pathology of the adrenal gland in Chshing's syndrome. J. Pathol. Bact. 93, 19-33.

Raux, M. C., M. Binoux, J. P. Luton, M. Gourmelen and F. Girard (1975). Studies of ACTH secretion control in 116 cases of Cushing's syndrome. J. Clin. Endocrinol. Metab. 40, 186-197.

Ruder, H. J., D. L. Loriaux and M. B. Lipsett (1974). Severe osteopenia in young adults associated with Cushing's syndrome due to micronodular adrenal disease. J. Clin. Endocrinol. Metab. 39, 1138-1147.

Sakiyama, R., M. W. Ashcraft and A. J. Van Herle (1984). Cyclic Cushing's syndrome. Am. J. Med. 77, 944-946.

Scott, H. W., G. W. Liddle, A. P. Harris and J. H. Foster (1962). A diagnosis and treatment of Cushing's syndrome. Ann. Surg. 155, 696-710.

Shenoy, R. V., P. C. Carpenter and J. A. Carney (1984). Bilateral primary pigmented nodular adrenocorcical disease : Rare cause of Cushing syndrome. Am. J. Surg. Pathol. 8, 335-344.

Shimizu, N. and K. Tanaka (1984). Cushing disease-Problems of its diagnosis and therapy. Naika Mook no. 25, Kanehara Press 120-125. (In Japanese).

Smals, A. G. H., G. F. F. M. Pieters, U. J. G. Healst and P. W. C. Kloppenborg (1984). Macronodular adrenocortical hyperplasia in longstanding Cushing's disease. J. Clin. Endocrinol. Metab. 58, 25-31. 